\title{
Effectiveness of counseling and correction of background factors of staff nurses on job satisfaction.
}

\author{
Mrs Esther. Sudhir. Joseph \\ Nursing Department/Krishna Institute of Medical Sciences University, Karad, Dist. Satara. \\ Maharashtra State. India
}

\begin{abstract}
Background: $60-75 \%$ of hospital operating cost is directly related to the personnel. Maximal utilization of human resources is of course related to employee's productivity. Concern must also be centered on employee motivation or more precisely on how the hospital provides employees, a change to satisfy their needs, which in turn produces motivation. Registered nurses account for a significant part of manpower expenditure in the hospitals. Hospital management face problems in terms of motivation, absenteeism and turnover.
\end{abstract}

Purpose: of the study was to assess the effectiveness of counselling and correction of staff nurses on job satisfaction in relation to her specific background factors.

Methods: A quasi experimental approach was adopted with a schematic representation of the design elements. The factors under study were the selected background factors, the job related factors and the personal factors. The conceptual framework was based on the Herzberg theory of motivation. Setting was located in the private hospitals of Nagpur, with population comprised of the staff nurses. A sample of 300 staff nurses was selected from seven different private hospitals through purposive sampling technique. The data collection technique was a self structured questionnaire, developed on job satisfaction and personal satisfaction. The teaching was carried out through a booklet on counseling and correction of background factors of staff nurses. The tool was developed in three parts i.e. personal information, factors of motivation and hygiene and factors related to personal satisfaction. Data was collected in three phases, from the sample subjects, after prior permission from the hospital administrator/medical superintendents.

The result indicated that after counseling and correction of the background factors of the staff nurses, maximum number of the nurses i.e. $75.33 \%$ were satisfied towards their job. $71.66 \%$ of nurses, those who were indifferent towards personal satisfaction, were found to be satisfied i.e. $64.66 \%$. The chi-square values indicated that there was no significant relationship between job satisfaction and specific background variables, however the involvement of the family members played an important role in the improvement of job satisfaction level. The $t$ value indicated that there was a significant relationship between job satisfaction and personal satisfaction. The study concludes that after counselling and correction of the background factors of staff nurses, the job satisfaction levels have improved from indifferent levels to satisfied levels. Similarly the significant improvement was observed in personal satisfaction levels of staff nurses i.e. from an indifferent level to a satisfied level. Hence it is concluded that there was a significant relationship of the involvement of family members in contributing toward job satisfaction of the staff nurses.

Key words: Background factors, counselling and correction, Job satisfaction, personal satisfaction, staff nurse.

\section{Introduction}

1.1 Background: Avallone et.al (1998) $)^{1}$ Hospitals are labor intensive organization with $60-75 \%$ of hospital operating cost is directly related to the personnel. The manager who does not consider the latest advances in manpower management cannot function optimally. One of the key considerations in maximal utilization of human resources is of course employee's productivity. Because of its relation to productivity, concern must also be centered on employee motivation or more precisely on how the hospital provides employees a change to satisfy their needs, which in turn produces motivation. Registered nurses account for a significant part of manpower expenditure in the hospitals. They also present serious problems for the hospital management in terms of motivation, absenteeism and turnover.

Anderson.A (1971) $)^{2} \mathrm{Job}$ satisfaction has been defined as a pleasurable state emotional state resulting from the appraisal of once job i) an affective reaction to one's job and ii)an attitude towards one's job iii) Weiss (2002) has argued that job satisfaction is an attitude but point out that researchers should clearly distinguish the objects of cognitive evaluation which are affect (emotions, beliefs and behaviours. This definition suggests that we form attitudes towards our jobs by taking into account our feelings, our beliefs and our behaviours. 


\subsection{A survey of the work done in the research area and the need for more research}

Blum L.M. (1955) ${ }^{3}$ Frequently, work underlies self-esteem and identity while unemployment lowers self worth and produces anxiety. At the same time monotonous jobs can erode a workers initiative and enthusiasm and can lead to absenteeism and unnecessary turn over. Job satisfaction and occupational success are major factors in personal satisfaction, self-respect, self-esteem, and self development. To the worker job satisfaction brings a pleasurable emotional state that often leads to a positive work attitude. A satisfied worker is more likely to be creative, flexible, innovative, and loyal.

Job satisfaction, a workers sense of achievement and success, is generally perceived to be directly linked to productivity as well as to personal well being. Job satisfaction implies doing a job one enjoys, doing it well, and being suitably rewarded for one's efforts. Job satisfaction further implies enthusiasm and happiness with one's work. The Harvard professional group (1998) sees job satisfaction as the keying radiant that that leads to recognition, income, promotion, and achievement of other goals that lead to general feeling of ful fillment.

Review of the studies conducted by Jayaseelam M. Devadason (1992) ${ }^{4}$, Jyoti kaul $(1989)^{5}$, revealed that job satisfaction was less than their job expectation. Benfort B. Longest $(1974)^{6}$ conducted studies in Job satisfaction among staff nurses. Freeman. T. (1998) ${ }^{7}$ conducted a study on factors influencing job satisfaction on specialty nursing units and found a positive correlation between autonomy, motivation and job satisfaction and found that neither gender was satisfied with their jobs in general.

Larson, Elaine $(1984)^{8}$ states that problems such as absenteeism, uncooperative or unproductive employees, clinical incompetence, and employees with emotional problems are challenge to a manager. These problems must be dealt within ways to minimize their effect on patient care and on staff morale.

There is also incompetent technical supervision that lacks knowledge of job or ability to delegate responsibility and teach. Working conditions, interpersonal relations, salary, lack of recognition and achievement can also cause dissatisfaction.

Hertzberg's theory describes two factors: Motivator factor and Hygiene factor. Motivator factor promotes job enrichment. Hygiene factors motivate workers by meeting the safety and security needs and avoiding job dissatisfaction. Today it is important for a nurse manager to use both Hygiene factor and Motivator factor in recruiting and retaining staff.

Job autonomy and ability to participate in decision making are important for maximizing satisfaction. $A$ happier nurse will deliver better patient care.

Quality assurance programs become more sophisticated and important to document adequate care to identify and solve problems and to demonstrate cost benefits of the program.

Nurses working in the hospitals have to face dissatisfaction. During their work, major part of the time is spent in work place. So it is important to understand satisfaction and dissatisfaction in her work situations and to explore how administration can help a nurse to minimize the dissatisfaction.

In context with the current population of nurses: While interviewing the nurses working in the private sector they reported dissatisfaction due to inflexible working arrangements, lack of training and professional growth opportunities, challenges of the job, no opportunities for counseling, more work load, less salary, and no job security, very less chances of promotion, lack of support from higher authorities, and problems of retention. The mortality reported was negligible as compared to morbidity which was around $30 \%$ to $40 \%$.

The nurses working in the govt. sector have more facilities as per the govt, rules like 1. Health benefits: leave benefits with pay, medical reimbursement, free investigation and treatment for their family members. 2 . Financial benefits: payment as per $6^{\text {th }}$ pay commission, loan facilities, uniform, washing and conveyance allowances etc. 3. Promotion benefits: on the job training and deputation, study leave with pay, promotional avenues. 4. Job security and retention of nurses is more. 6. Regularity of pay and pension benefits etc.

The Hitavada of (May 2012) ) $^{9}$ reports that the nurses working in the private sector have filed PIL for enforcement of fundamental rights of working professional nurses under article 14, 19, and 21 as they reported harassments from their employer. The Supreme Court has sought response of the centre and state govt. for framing guidelines for private hospitals to prevent them from the harassments.

Researcher's work experience as a nurse manager has motivated her to investigate staff nurse's job satisfaction in hospital setting.

\section{Objectives}

1. To determine the level of Job satisfaction among staff nurses before and after counseling and correction of background factors

2. To determine the association between job satisfaction and selected background variables.

3. To determine the level of personal satisfaction among staff nurses before and after counseling and correction of background factors. 


\section{Hypothesis}

The following hypothesis was formulated for the study:

$\mathrm{H}_{1} \quad$ There will be a significant relationship between job satisfaction before and after counseling and correction of background factors of the staff nurses as evident from the structured questionnaire at 0.05 level of significance.

$\mathrm{H}_{2} \quad$ There will be a significant relationship between job satisfaction and background variables of staff nurses as evident from the structured questionnaire at 0.05 level of significance

A There will be a significant relationship between job satisfaction and age of the staff nurses as evident from the structured questionnaire at 0.05 level of significance.

B There will be a significant relationship between job satisfaction and marital status of the staff nurses as evident from the structured questionnaire at 0.05 level of significance.

C There will be a significant relationship between job satisfaction and duration of experience of the staff nurses as evident from the structured questionnaire at 0.05 level of significance.

D There will be a significant relationship between job satisfaction and number of dependents of the staff nurses as evident from the structured questionnaire at 0.05 level of significance.

E There will be a significant relationship between job satisfaction and employment of the husband/other family members of the staff nurses as evident from the structured questionnaire at 0.05 level of significance.

F There will be a significant relationship between job satisfaction and support of the family of the staff nurses as evident from the structured questionnaire at 0.05 level of significance.

G There will be a significant relationship between job satisfaction and relationship with family members of the staff nurses as evident from the structured questionnaire at 0.05 level of significance.

$\mathrm{H} \quad$ There will be a significant relationship between job satisfaction and family income of the staff nurses as evident from the structured questionnaire at 0.05 level of significance.

$\mathrm{H}_{3} \quad$ There will be a significant relationship between personal satisfaction before and after counseling and correction of background factors of the staff nurses as evident from the structured questionnaire at 0.05 level of significance.

\section{Methodology And Techniques}

a) Research Approach: A quasi experimental approach was adopted as per the nature of the study, to assess the effectiveness of counselling the staff nurses in context to her specific background factors of staff nurses working in the Private Hospitals.

b) Research Design: one group pre-test post test design was adopted as per the nature of the study. Schematic representation of the design elements of the study.

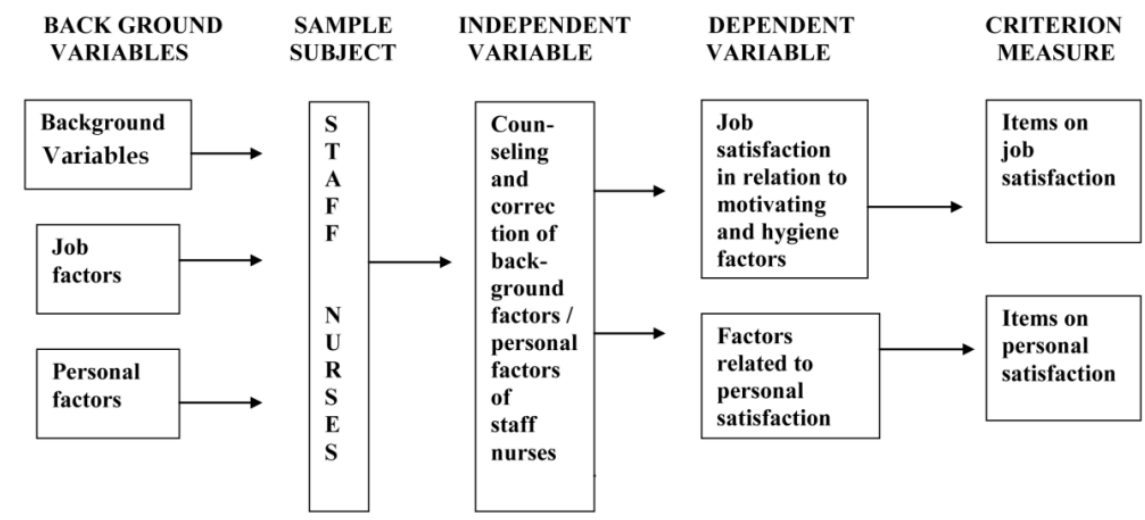

Schematic Representation of the Design Elements of the Study.

Keeping in view the objectives of the study the design was developed to enable the investigator to study the relationship between job satisfaction, selected background factors and personal factors. The identified background variables included in this study are:

4.1 Background variables: 1.Age, 2. Marital status, 3.Type of family, 4.Religion, 5.General Education, 6. Number of dependents, 7. Professional Education, 8.length of service, 9. Employment of the husband/other family members 10 . Husband /other family members supporting in domestic work.11.Relationship with family members 12 .Family atmosphere, 13. Family income. 
Effectiveness of counseling and correction of background factors of staff nurses on job satisfaction.

\subsection{Job related factors:}

Motivating Factors: 1. The work itself, 2. Achievement, 3. Growth \& advancement, 4. Recognition, 5. Responsibility.

HygieneFactors:1.Policy\&Administration, 2.Workingcondition, 3. Supervision, 4. Interpersonal relation, 5. Salary status \& Security.

4.3 Personal factors: 1. Pertaining to the role performance in the family 2. Pertaining to the self development 3. Pertaining to the health aspects 4 . Pertaining to the financial aspects 5. Pertaining to the adjustments in the family.

Counseling and correction in the areas of personal background factors in respect of staff nurse was carried out through a teaching plan. Counseling was conducted in groups of staff nurses in a direct approach method. Correction was done by advising/guiding/suggesting the staff nurses on using the best options related to personal satisfaction factors.

Conceptual framework is based on the concepts drawn from the Herzberg $(1986)^{10}$ theory of motivation. According to Herzberg if someone is satisfied with his job, he is receiving a positive feed back and developing skill and improving his performance. Herzberg maintains that an employee can be motivated by giving him challenging work that he can cope with.

4.4 Setting: Private Hospitals of Nagpur in which registered staff nurses are employed.

4.5 Population: Staff nurses working in the Private Institutions at Nagpur.

4.6 Sample size: 300 Staff nurses from the selected Private hospitals:

1. Mure Memorial Hospital, Nagpur $=50$

2. Lata Mangeshkar Hospital, Nagpur $=50$

3. Wockhardt Hospital, Nagpur $=80$

4. Care Hospital, Nagpur $=50$

5. Suretech Hospital, Nagpur $=50$

6. Central India Institute of Medical Sciences Hospital, Nagpur $=10$

7. Matru Seva Sangh, Buldi, Nagpur $=10$

Sample size of staff nurses was estimated assuming $25 \%$ of the staff nurses are satisfied with their job. A total of 288 nurses are required to estimate the proportion with a relative precision $=25 \%$ and $95 \%$ confidence level. Therefore 300 staff nurses were included in the study and from seven hospitals nurses participated in the city.

4.7 Sampling Technique: Keeping in mind the availability of the sample, Purposive sampling technique was used. The sample consisted of 300 staff nurses working in selected private hospitals in Nagpur. Also Selected the sample of 300 nurses from only those hospitals whose management permitted the nursing staff to participate in the study.

4.8 Study duration: was from October 2008 to September 2013.

\subsection{Criteria for selection of sample:}

Inclusion criteria:

1. Must be a registered Nurse and Midwife with one year of experience.

2. Staff nurses who are willing to participate in the study with minimum qualification of GNM.

3. Who are available on the day of data collection.

4. Staff nurses who can read, write and understand English.

Staff nurses with minimum one year of experience are included in the study because within the first year of experience, the magnitude of dissatisfaction is felt more in the younger generation. As they are continuously moving, comparing and searching for better alternative options

Hence it was decided to include the nurses with minimum one year of experience.

\section{Exclusion criteria:}

1. Staff nurses with serious illness.

2. Staff nurses who have undergone the course on counseling and correction of personal/ background factors.

3. Male staff nurses.

4. Staff nurses who are not willing to participate in the study.

Nursing profession is mainly dominated by female nurses in India. As only female nurses are included in the study the word "Her" in the title is used. 
4.10 Data Collection technique: The purpose of the study was to inquire into the factors of job satisfaction and personal satisfaction as perceived by the staff nurses working in the private institutions. In order to collect information more systematically, a Self structured Questionnaire was developed and used for the study. A teaching plan was adopted through a booklet on counseling and correction of background factors for staff nurses was developed keeping in mind to assess the nurses before and after counseling and correction of background factors. It is recognized that self administered questionnaire helps to maintain the anonymity of the staff nurses, ensuring free and frank opinion/responses from them.

4.11 Development of the tool: Through review of related literature, review of studies conducted on the topic, Informal discussion with the staff nurses in the private institutions, professional experience of the investigator as a nurse administrator

Part -I It contained items for obtaining personal information with regard to 1. Age, 2. Marital status, 3.Type of family, 4.Religion, 5.General education, 6.Number of dependents, 7. Professional Education, 8.length of service, 9.Employment of the husband/other family members, 10.Husband /other family members supporting in domestic work. 11. Relationship with family members 12. Family atmosphere, 13. Family income.

Part -II It consisted of questions to identify condition / factors related to motivation and hygiene factors. The motivating factors were 1 . The work itself 2 . achievement 3 . growth and advancement 4 . recognition 5 . responsibility. The hygiene factors were 1. policy and administration 2. working conditions 3 . supervision 4 . interpersonal relation 5 . salary status and security.

The number of items in this area were 73 and the maximum possible score were 365 . For each question there was provision of selecting one out of five possible responses in a five point scale (likart scale). The satisfaction scores were made on $20 \%$ basis.

Part - III It consisted of conditions/factors related to personal satisfaction which were 1. Pertaining to the role performance in the family 2 . pertaining to the self development 3 . pertaining to her health aspects 4 . pertaining to the financial aspects 5 . pertaining to the adjustments in the family.

The number of items in this area were 40 and the maximum possible score were 200. For each question there was provision of selecting one out of five possible responses in a five point scale(likart scale). The satisfaction scores were made on $20 \%$ basis.

4.12 Content Validity: Questionnaire on background factors, job and the booklet on personal counseling, and correcting the background factors of staff nurses were submitted to 12 experts in the field of nursing administration, nursing education and psychologist and necessary modifications was made.

4.13 Reliability: was computed using Cronbach Alpha formula. The reliability coefficient was found to be 0.81 for job satisfaction tool, and 0.77 for personal satisfaction tool. The informational booklet on counseling and correction of background factors for staff nurses was mostly agreed on its content, relevancy, comprehensiveness, and usefulness. The tool was found to be valid, feasible and reliable.

4.14 Pilot Study: Was conducted in the Central India Institute of Medical Sciences, Nagpur, on 60 staff nurses working in that institute.. The pilot study helped to find out the feasibility of the project and selection of suitable statistical methods.

4.15 Procedure for data collection: Former permission was sought from the hospital administrator/ Medical superintendent of the related hospital to conduct the final study. Data was collected from the staff nurses of the selected private hospitals for one year in the phased manner. The structured Questionnaire was used for data collection.

With the help of Nurse Managers, staff nurses were met and explained the purpose of the study and questionnaire. They were assured of confidentiality and anonymity of their responses.

Purposive sampling technique was used to collect from the above mentioned registered staff nurses at Nagpur.

Data was collected from sample subjects who are readily available during the period of data collection. Self introduction of investigator to the individual nurses was done and questionnaire were distributed and collected back the same day.

Phase I - data was collected from the sample subjects from January 2009 to $\quad$ March 2009 for job satisfaction, and personal satisfaction

Phase II- Counseling and correction technique through a teaching plan was implemented for background/personal factors from April 2009 to May 2009 through direct counseling method in the respective hospitals for group of nurses. Informational booklet was referred.

Phase III-data was collected again from October 2009 to December 2009 after counseling and correcting the background factors of staff nurses for job satisfaction, personal satisfaction.

4.16 Ethical and legal aspects: No major ethical or legal issues were involved in this study as this was a quasi experimental study where no invasive procedures were involved. Nurses were only questioned regarding their satisfaction and the intervention of counseling and correction of background/personal factors did not harm the nurses or the institution. However informed consent of the participant was sought after explaining the purpose of the study and the importance of the study. Moreover permission from the hospital management was obtained. 


\section{Major Findings}

Major findings of the study was computed in relation to:

1. Findings related to sample characteristics

2. Findings of job satisfaction, before and after counseling and correction of background factors.

3. Findings related to relationship between job satisfaction and background variables.

4. Findings of personal satisfaction, before and after counseling and correction of background factors.

\section{Main Findings Of The Study}

6.1. Findings Related To Sample Characteristic : $: 73.33 \%$ of staff nurses belonged to age group of 21-30 years. $40.66 \%$ of the nurses were married. $66.66 \%$ belonged to nuclear families. Majority of the nurses were Hindu. $96 \%$ of staff nurses had their professional education as GNM nurses. $25.66 \%$ of the family members were unemployed and $24.66 \%$ of nurses had a partially supportive atmosphere.

\subsection{Findings On Job Related Satisfaction Before Counseling And Correction Of Background Factors Of} Staff Nurses Were:

A) The mean was 173.2 , median 169.547 and standard deviation was 152.89 .

B) Maximum number of nurses i.e. 223 (74.33\%) were indifferent towards job satisfaction.

C) The maximum satisfaction area was identified as supervision followed by the work itself.

D) The least satisfaction area was identified as growth and advancement and policy and administration.

\subsection{Findings On Job Related Satisfaction After Counseling And Correction Of Background Factors Of} Staff Nurses Were:

A) The mean was 282.667 , median 286.5 (fig 1) and standard deviation was 98.686 .

B) Maximum number of nurses i.e. $226(75.33 \%)$ were satisfied towards job satisfaction.

C) The maximum satisfaction area was identified as the work itself followed by supervision.

D) The least satisfaction area was identified as growth and advancement and policy and administration.

6.4. Findings Related To Relatioship Between Job Satisfaction And Background Variables: It was inferred that job satisfaction by staff nurses was not dependent on the background variables of age, marital status, duration of experience, number of dependents, employment of husband/other family members, family members supporting in domestic work, and family income, but they were found to be dependent on relationship with family members.

6.5. Findings Of Personal Satisfaction Before Counseling And Correction Of Background Factors Of Staff Nurses Were:

A) The mean was 95.86, median 92.848 and standard deviation was 328.44.

B) Maximum number of nurses i.e. $215(71.66 \%)$ were indifferent towards personal satisfaction.

C) The maximum satisfaction area identified as pertaining to her role performance in the family followed by adjustments in the family.

D) The least satisfaction area was identified as pertaining to her financial aspects and pertaining to her self development.

6.6. Findings Of Personal Satisfaction After Counseling And Correction Of Background Factors Of Staff Nurses Were:

A) The mean was 181.733 , median 162.210 (fig 2) and standard deviation was 120.231 .

B) Maximum number of nurses i.e. 194 (64.66\%) were satisfied towards personal satisfaction.

C) The maximum satisfaction area identified as pertaining to her role performance in the family followed by adjustments in the family.

D) The least satisfaction area was identified as pertaining to her health aspects and pertaining to her self development.

\section{Conclusions}

It is concluded that after counseling and correction of background factors of staff nurses:

1. The job satisfaction level of staff nurses have increased from an indifferent level to a satisfied level.

2. Maximum satisfaction area identified was the work itself and supervision.

3. Least satisfaction areas were growth and advancement and policy and administration.

4. The personal satisfaction level of staff nurses have increased from an indifferent level to a satisfied level.

5. Maximum satisfaction area identified was pertaining to her role performance in the family followed by adjustments in the family. 
6. The least satisfaction areas were pertaining to her health aspects and self development.

7. The scores pertaining to the areas of job satisfaction, and personal satisfaction obtained were definitely higher after counseling and correction of background factors of staff nurses suggesting that counseling and correction of staff nurses on their background factors is an effective tool to improve upon their job satisfaction, personal satisfaction.

8. The chi-square values obtained indicated that there is no significant relationship between job satisfaction and specific background variables among the staff nurses except for the relation ship with the family members which was found to be significant.

9. The t value obtained for job satisfaction, personal satisfaction before and after counseling and correction of background factors of staff nurses indicated that there was a significant relationship for job satisfaction (table 1) and personal satisfaction of the staff nurses (table 2)

10. It was concluded that counselling and correction of nurses on background factors is always possible through the nursing managers, as it enables the nurses to perform better in their jobs and personal lives, and that job satisfaction can be correlated with life's satisfaction.

11. This study is useful to all the nursing managers of private organizations in leading the nurses in the right direction pertaining to the nurse's job.

12. This study is limited to staff nurses working in the private settings/organizations and the factors related to personality, emotions etc which may have influenced job related satisfaction, are not under study.

13. Application: The application of such study will be useful for improvement of the satisfaction levels of staff nurses in their jobs.

14. Extension: The effectiveness of the study can also be acquired in respect of other professions like factory workers, school teachers and non technical staff.

Job related satisfaction areas before and after counseling and correction of background factors

\begin{tabular}{|c|c|c|c|c|}
\hline 2 & Achievement & 16.956 & 27.65 & \\
\hline 3 & Growth and advancement & 15.493 & 25.993 & \\
\hline 4 & Recognition & 17.2 & 27.53 & \\
\hline 7 & Working conditions & 16.326 & 26.8 & \\
\hline 8 & Supervision & 19.763 & 30.33 & \\
\hline 9 & Interpersonal relations & 18.546 & 28.063 & \\
\hline 10 & Salary safety and security & 16.253 & 28.496 & \\
\hline
\end{tabular}

Data in table 1 reveals that the mean scores on job satisfaction after counseling and correction of background factors of staff nurses were higher than the mean scores on job satisfaction before counseling and correction of background factors of staff nurses in all the ten areas of satisfaction.

The " $t$ " value obtained was 9.20 which is significant at 0.05 level. Thus, the result indicates that there was significant relationship between job satisfaction before and after counseling and correction of the background factors of staff nurses. Therefore the research hypothesis $\mathrm{H}_{1}$ is accepted and null hypothesis is rejected.

\section{Areas related to personal satisfaction before and after counseling and correction of background factors}

$$
\mathbf{N}=\mathbf{3 0 0}
$$

\begin{tabular}{|c|l|c|c|c|}
\hline S. No. & Personal factors related to satisfaction areas & $\begin{array}{c}\text { Mean before } \\
\text { counseling and } \\
\text { correction of } \\
\text { background factors }\end{array}$ & $\begin{array}{c}\text { Mean after counseling } \\
\text { and correction of } \\
\text { background factors }\end{array}$ & $\begin{array}{c}\text { T } \\
\text { value }\end{array}$ \\
\hline 1 & $\begin{array}{l}\text { Pertaining to her role performance in the } \\
\text { family }\end{array}$ & 19.48 & 31.916 & $\mathbf{t}=$ \\
\hline 2 & Pertaining to her self development & 18.87 & 30.86 & 30.673 \\
\hline 3 & Pertaining to her health aspects & 19.033 & 30.906 & 31.423 \\
\hline 4 & Pertaining to her financial aspects & 18.846 & 19.036 & \\
\hline 5 & Pertaining to her adjustments in her family & & & \\
\hline
\end{tabular}

Data in table 2 reveals that the mean scores on personal satisfaction after counseling and correction of background factors of staff nurses were higher than the mean scores on personal satisfaction before counseling and correction of background factors of staff nurses in all the five areas of satisfaction. 
The " $t$ " value obtained was 6.17 which is significant at 0.05 level. Thus, the result indicated that there was significant relationship between personal satisfaction before and after counseling and correction of the background factors of staff nurses. Therefore the research hypothesis $\mathrm{H}_{3}$ is accepted and null hypothesis is rejected.

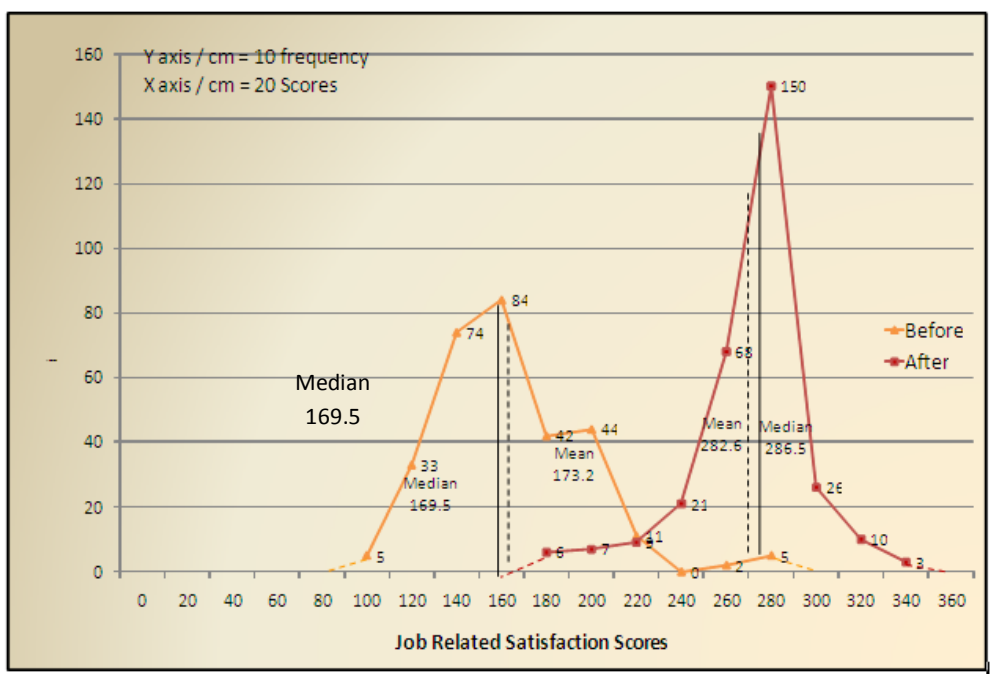

Fig. 1. Smoothened frequency polygon showing distribution of Job Related Satisfaction scores of Staff Nurses before and after counseling and correction of background factors.

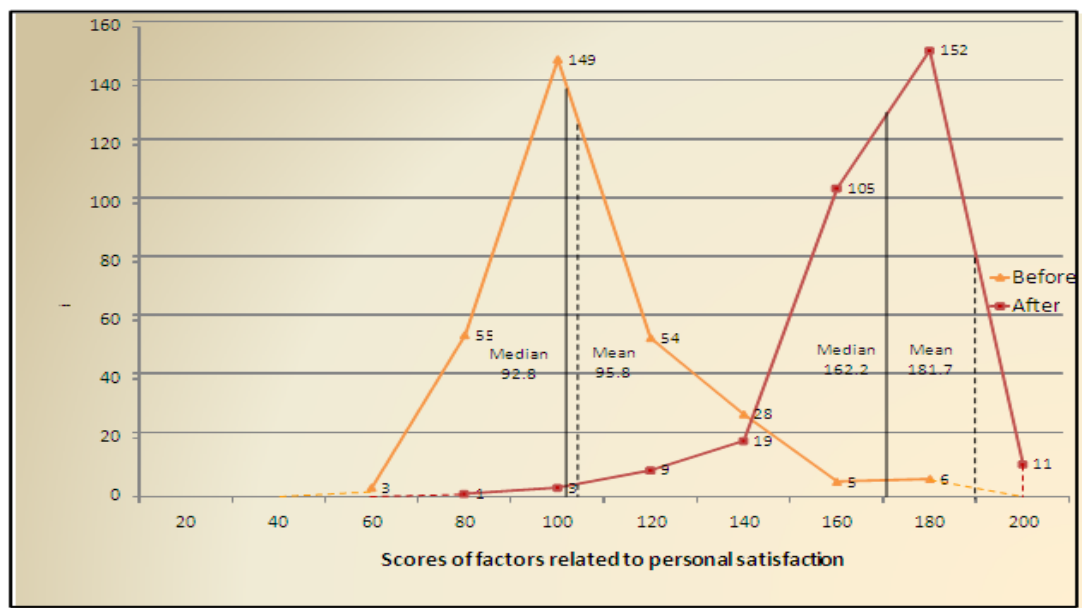

Fig. 2. Smoothened frequency polygon showing distribution of factors related to personal satisfaction scores of Staff Nurses before and after counseling and correction of background factors.

\section{Disscussion}

The present study was undertaken to determine the level of job satisfaction of staff nurses and to compare job satisfaction before and after counseling and correction of background factors of staff nurses. The present study showed that nurses reported a wide in satisfaction before and after counseling and correction of background factors. There were several factors which intervened between the situation and the experience of dissatisfaction such as growth and advancement, supervision, working conditions etc. which could be the reason for the variations in dissatisfaction experienced. Counseling and correction of personal factors not only enhanced the morale of the nurses, but also increased their satisfaction levels in their jobs, and personal life.

One common research finding is that job satisfaction is correlated with life satisfaction. People who are satisfied with life tend to be satisfied with their job, and people who are satisfied with their job tend to be satisfied with life. An important finding for organizations to note is that job satisfaction has a correlation to productivity on the job.

The meta analysis found that relationship between satisfaction and performance can be moderated by job complexity such that for high complexity jobs the correlation between satisfaction and performance is higher than for jobs of low moderate complexity. 
The findings of the present study are in agreement with the study conducted by Devadason M.J.(1992) ${ }^{4}$ who reported majority of the nurses had low job satisfaction in growth and advancement and supervision. Research studies done by Kaul J. (1989) ${ }^{5}$ and Agrawal C.K(1972) ${ }^{11}$ revealed that job satisfaction experienced by the staff nurses was not dependent on background factors of age, marital status, duration of experience, number of dependents, employment of family members, support of family but it was dependent on relationship with family members.

Robinson E. $(2006)^{12}$ reported a significant relationship between job satisfaction and personal satisfaction.

Wu Si Ying $(2012)^{13}$ reported in her study on Chinese nurses that stressors were closely associated with quality of life which is mediated and moderated by personal strain and coping resources. Personal strain also acted both as moderator and mediator in relationship between coping resources and quality of life. An effective intervention strategy is needed to reduce work stress, personal stress and ensure better quality of life through counseling methods.

The study conducted by Shui-Tao $(2007)^{14}$ on effectiveness of application counseling programme competence and satisfaction for nurses in Japan reports that following counseling programme the mean satisfaction scores for the nurses was significantly increased. The result concluded that implementing the counseling programme method could effectively enhance satisfaction of the nurses thereby enhancing their competence of nursing in their work place.

LynnPonton $(2006)^{15}$ in her study reports that effective counseling and correction of background factors of nurses is a two way process involving the cooperative efforts by both the person receiving counseling and the counselor. A good counselor can assist in making positive changes in your relationship and help you recognize behaviors that may be contributing to a troublesome relationship. The end result is the personal growth that empowers you to control your life and enjoy a positive relationship with others.

Morland (1999) ${ }^{16}$ in her study on effective of supportive counseling programme on personal behaviors of nurses reports that nurses experience stress bringing about somatic diseases, mental health disorder, and feeling of exhaustion. The study concludes that the nurses who participated in the supportive counseling programme had reduced problems concerning their personal behaviors, and were able to cope up with life in their institution.

All the above studies has supported the fact that enhancement of background factors/personal factors of nurses have a positive impact in their jobs as well as their personal lives.

7.1 Implications This study had its implications in the field of nursing practice, nursing education, nursing administration, and nursing research was identified.

7.2 Recommendations On the basis of findings, recommendations were made.

\section{Acknowledgements}

This research project has been under taken under the expert guidance and supervision of Dr. P.G. Chougule Head of the department of Surgery at Krishna Institute of Medical Sciences University, Karad, Satara (M.S.) I express my sincere gratitude for his suggestions and constant encouragement throughout my study.

I am highly obliged to the Controller of Examinations, the Dean, and the entire teaching faculty of the University for helping me in the successful completion of the study.

My sincere thanks to the authorities of the private hospitals for granting me permission and my special thanks to all the staff nurses for their cooperation and participation in the project.

An expression of deep and warm thanks to my husband Mr. Sudhir Joseph and my children Jonathan and Eliab who tolerated stress and strain due to their Mom's preoccupation with the project.

Above all I thank the Almighty God for His abiding grace and faithfulness.

Journal papers:

\section{References}

[1]. Avallon et. al. Nurses Perception of their Work Environment in a Nursing Development Unit. Journal of Advance Nursing 26(6), 1998, 193-201

[2]. Anderson A. Nurse Physician interaction and Job Satisfaction, Nursing Management 27(6), June1996, 33-34

[3]. Longest B. Satisfaction for Registered Nurses in Hospital Setting, The Journal of Nursing Administration 4(3), May-June 1974, 4652

[4]. Freeman T. Factors Influencing job satisfac25-51, tion in Speciality Nursing units, Canadian Journal of Nursing Administration 11(3), sept-oct 1998,

[5]. Larson Elaine Job Satisfaction Assumption and Complexities The Journal of Nursing Administration 14(1), Jan1984, 31-37,

[6]. Robinson E. Effective Counselling Methods ABNF Journal 7(5), July 2006, 109-111

[7]. Wusiying Predicators of Job Satisfaction, Turnover and Burnout Journal of Nursing Research 2(6), 2012, 50-65

[8]. Shitao Effectiveness of Application Counseling Programme Journal of Advance Nursing 7(12), 2007, 193-201

[9]. Lynn pontin Effective Counseling Methods ABNF Journal 7(5), 2006, 109-111

[10]. [10] Morland et.al. Supportive Counseling programmes on Personal Behaviours of Nurses, Journal of Nursing Administration 28(6), June1999, 152-160 
[11]. Books:

[12]. Blum L M. Job Satisfaction, Industrial Psychology and its Social Foundation, Newyork, Harper and Brothers publishers,1956 , 154155

[13]. Herzberg,Polit Nursing Research Principles and Methods, Philadelphia, J.B. Lippincot Company 1986

[14]. Theses:

[15]. Devadason J M. A study to ascertain the level of job satisfaction among male nurses in Bangalore in relation to selected background factors Unpublished Masters of Nursing Dissertation, University of Delhi 1992

[16]. Kaul Jyoti Job Satisfaction of staff nurses in Medical College associated group of Hospitals in Srinagar, Unpublished Masters of Nursing Dissertation, University of Delhi 1989

[17]. Agrawal C.K. A Comparative study of the levels of job satisfaction in medical colleges at Ajmer, Unpublished Masters of Nursing Dissertation, University of Delhi 1972

[18]. Papers:

[19]. The Hitavada The fundamental rights of Nurses Colum 4, 2, May 2012 